\title{
PROPOSTA DE CONSCIENTIZAÇÃO SOCIOAMBIENTAL PARA EMPRESA: ESTUDO DE CASO NA ULTRAECO
}

\section{ARTIGO ORIGINAL}

BARRETO, Vanessa Souza1', MEZA, Maria Melissa Monteiro², DIAS, Vinicius Rocha Ribeiro ${ }^{3}$, ALMEIDA, Victor da Silva ${ }^{4}$, ROBERTO, José Carlos Alves ${ }^{5}$

\section{BARRETO, Vanessa Souza. Et al. Proposta de conscientização socioambiental} para empresa: estudo de caso na Ultraeco. Revista Científica Multidisciplinar Núcleo do Conhecimento. Ano. 06, Ed. 11, Vol. 14, pp. 109-137. Novembro de 2021. ISSN: 2448-0959, Link

de acesso:

https://www.nucleodoconhecimento.com.br/administracao/conscientizacaosocioambiental, DOI:

10.32749/nucleodoconhecimento.com.br/administracao/conscientizacaosocioambiental

\section{RESUMO}

O presente estudo de caso, foi realizado na empresa Ultraeco, que emprega práticas sustentáveis em seus processos para a lavagem de veículos. O artigo busca apresentar a lavagem a seco ao público, principalmente ao nicho de mercado de consumidores que optam por produtos ou serviços sustentáveis. Baseando-se neste conceito, o artigo tem como pergunta problema: Como a implementação de ações sustentáveis podem colaborar como estratégias de marketing para captação de clientes? O objetivo geral é definir uma estratégia que englobe a questão socioambiental, focalize na captação e fidelização dos clientes e tenha uma

\footnotetext{
${ }^{1}$ Graduando do curso de Administração.

${ }^{2}$ Graduando do curso de Administração.

${ }^{3}$ Graduando do curso de Administração.

${ }^{4}$ Coorientador. Mestre em Engenharia de Processos. Pós-Graduando em Neuropsicopedagogia Institucional. Especialista em Gestão Estratégica de RH. Graduado em Administração e Pedagogia.

${ }^{5}$ Orientador. Mestrado profissional em Engenharia de produção. Especialização em Gestão em Logística empresarial. Graduação em Administração com Ênfase em Marketing.
}

RC: 102274

Disponível em:

https://www.nucleodoconhecimento.com.br/administracao/conscientizacao- 
preocupação com a redução da utilização dos recursos naturais, o que, consequentemente, pode contribuir para que a empresa tenha um diferencial mercadológico. O método utilizado para realização da pesquisa foi o dedutivo, por meio da pesquisa de campo, utilizou-se também a pesquisa bibliográfica. Como resultados, a proposta interventiva prevê a utilização de investimentos em práticas operacionais sustentáveis inovadoras, a utilização do endomarketing para consolidar as práticas sustentáveis no ambiente interno da organização, a geração de relatórios dos impactos da redução de recursos naturais, e, a partir deste conjunto de ações, estabelecer um plano de divulgação das práticas sustentáveis da organização, buscando a captação de clientes que optam por consumir produtos e serviços de empresas que praticam conceitos sustentáveis. A proposta do artigo atende o propósito de transmitir ao público externo os resultados que a empresa Ultraeco vem alcançando por meio da gestão sustentável, tornando a empresa atrativa para os consumidores de produtos e serviços sustentáveis.

Palavras-chave: Sustentabilidade, Meio ambiente, Lavagem Ecológica, Gestão Sustentável.

\section{INTRODUÇÃO}

Com o passar dos anos, as empresas perceberam a necessidade de buscar por gestões sustentáveis, visando a preservação dos recursos retirados do meio ambiente. Isso seria possível caso incluíssem em suas linhas de produção matériasprimas ecológicas ou reutilização em seus processos, o que também seria vantajoso para as empresas, pois ajudaria na captação e fidelização de futuros clientes que demonstram ter certo apreço pelo nicho das práticas sustentáveis.

A empresa Ultraeco, objeto de análise deste estudo, demostra grande preocupação com a questão de fornecer um serviço/produto que não prejudique o meio ambiente, e, após inúmeras pesquisas, o fundador encontrou uma forma de oferecer um método inovador para lavagem de veículo sem gerar impactos ao ecossistema.

RC: 102274

Disponível em:

https://www.nucleodoconhecimento.com.br/administracao/conscientizacao-

socioambiental 
Neste contexto, a questão norteadora é: Como a implementação de ações sustentáveis podem colaborar como estratégia de marketing para captação de clientes? Tem como objetivo geral, definir uma estratégia que englobe a questão socioambiental, focalize na captação e fidelização dos clientes, e demonstre preocupação com a redução do consumo de água, o que, consequentemente, contribuirá para que a empresa permaneça com sua visibilidade e se desenvolva cada vez mais.

Estabelece-se como objetivos específicos: Gerar relatórios dos impactos na redução do consumo de recursos naturais, controlar o consumo da água descrevendo os impactos ecossistêmicos e os benefícios sustentáveis da empresa, e abordar o uso da sustentabilidade como estratégia de marketing em seus produtos e serviços.

\section{FUNDAMENTAÇÃO TEÓRICA}

Como afirma Minayo et al. (2020), é necessário que um artigo tenha embasamento teórico e uma breve introdução do assunto que será abordado no item. Para isto, é necessário acrescentar citações. A fundamentação teórica possui uma estrutura básica que deve ser desenvolvida da maneira correta, sendo os elementos que fazem parte da sua base: pré-textuais, textuais e pós-textuais.

De acordo com Azevedo (2017), podemos afirmar que a fundamentação é um conjunto de referenciais teóricos que evidenciam o que o autor quis transparecer a partir da conclusão feita por meio da análise de dados coletados na pesquisa. $O$ artigo tem essa parte justamente para que o público externo compreenda qual foi o objetivo central do estudo e quais são os resultados propostos a serem alcançados.

\subsection{GERAR RELATÓRIOS DOS IMPACTOS NA REDUÇÃO DE CONSUMO DOS RECURSOS NATURAIS}

Controlar a quantidade de água consumida tem efeitos significativos, principalmente, para o meio ambiente. De acordo com Martins et al. (2020), por mais que o planeta

RC: 102274

Disponível em:

https://www.nucleodoconhecimento.com.br/administracao/conscientizacaosocioambiental 
disponibilize água em abundância, somente $1 \%$ dessa água pode ser utilizada por seres vivos. Grande parte da água existente no planeta é do tipo salgada, o que impossibilita que os seres humanos usufruam dela, o restante se encontra em geleiras ou regiões escondidas.

De acordo com Both e Fischer (2017), a partir de uma construção harmônica entre desenvolvimento econômico, justiça social e preservação do meio ambiente, acontecerá o desenvolvimento sustentável. Como consequência, ocorrerá uma melhora na qualidade de vida, os recursos naturais nas empresas serão utilizados de forma mais consciente e, esse tipo de ação, ajudará na redução do consumo desenfreado pela sociedade.

Ao se deparar com esses fatores, a empresa Ultraeco, teve a preocupação de pesquisar um método de lavagem, cujo consumo de água fosse mínimo. O fundador conseguiu encontrar uma forma para que a lavagem de veículos se tornasse sustentável, utilizando produtos que não causassem danos ao meio ambiente. Assim, foi implementada a técnica da lavagem ecológica de veículos, que é disponibilizada aos clientes.

A geração de relatórios para acompanhar a redução de água é indispensável para acompanhar o impacto positivo que esta atitude causa no meio. Além disso, o relatório é primordial para a coleta de dados fundamentais ao setor de marketing da empresa.

\subsubsection{O QUE FAZER PARA O CONTROLE DO CONSUMO DE ÁGUA?}

Segundo Laranjeira (2019), a politização do consumo da água deveria ser para todos, visto que utilizamos um grande volume de água no dia a dia. A água é um recurso natural que esteve presente em abundância durante muitos anos, porém, com o aproveitamento inapropriado do ser humano ela tem se tornado um recurso escasso. A forma mais eficiente para continuarmos usufruindo desse recurso é a reciclagem ou o reuso de água. Pensando nisto, a empresa Ultraeco tem uma visão

RC: 102274

Disponível em:

https://www.nucleodoconhecimento.com.br/administracao/conscientizacaosocioambiental 
diretamente voltada à restrita utilização de água em seus serviços, ou seja, sua lavagem gera um gasto mínimo de água, podendo ser considerada uma lavagem ecológica.

Segundo Rodrigues et al. (2016), os lava-jatos precisam de orientação ao serem inaugurados, para que haja um controle do seu consumo e conservação de água. Se faz necessário um planejamento de ações para armazenamento adequado de águas pluviais para reuso e utilização de produtos biodegradáveis, a fim de que não ocorra poluição. Normalmente, esses lava-jatos funcionam ilegalmente, sem uma fiscalização correta. Esse tipo de estabelecimento é o principal rival da Ultraeco, visto que ambos têm o mesmo foco de serviço, mas com processos contrários.

O controle que a Ultraeco estabeleceu é o de uso da água na diluição dos produtos, de forma que seja utilizado o mínimo de água possível, mas sem que isso atrapalhe no rendimento e lucratividade do negócio. A empresa utiliza cerca de $500 \mathrm{ml} \mathrm{a} 1 \mathrm{~L}$ de água por lavagem, comparando a lavagem tradicional isso representa uma economia de $300 \mathrm{~L}$ a $500 \mathrm{~L}$ por lavagem. Com esta prática, a Ultraeco já economizou mais de 3 milhões de litros de água desde sua adoção.

\subsubsection{DESCREVER OS IMPACTOS ECOSSISTÊMICOS}

A conscientização é um trabalho árduo que vem sendo feito há algum tempo por algumas ONGs, pelo governo e por instituições não governamentais. Ultimamente, as empresas vêm adotando uma gestão ambientalista para poder minimizar os impactos causados no meio ambiente. Segundo Filho (2017), a utilização da água nos processos habituais do ser humano ocasiona poluição, pois, a partir do momento em que não há controle do processo produtivo, dos materiais utilizados e do armazenamento, haverá contaminação pela utilização indevida.

De acordo com Nascimento (2021), nos últimos anos tem ocorrido um avanço do derretimento das calotas polares, no desmatamento e na poluição, colaborando para uma possível escassez de recursos naturais. Diante dessa situação, a empresa

RC: 102274

Disponível em:

https://www.nucleodoconhecimento.com.br/administracao/conscientizacaosocioambiental 
estudada, conscientemente, induz seus clientes a economizarem água ao dar preferência à lavagem ecológica.

\subsubsection{OBSERVAR OS BENEFÍCIOS PARA A GESTÃO SUSTENTÁVEL DA EMPRESA}

O uso excessivo de recursos provenientes do meio ambiente não era a maior preocupação das empresas de antigamente, o foco principal era o produto final e o lucro que seria gerado pela venda deste. Com o passar dos anos, o conceito de sustentabilidade ganhou importância, visto que a maioria das empresas observaram que ter uma gestão que englobasse técnicas inovadoras com o viés sustentável, juntamente com métodos de aproveitamento de materiais e recursos, criou um vínculo que o mercado estava exigindo, sem deixar de lado a busca por manter a economia da empresa em constante crescimento.

Portanto, podemos entender a gestão sustentável como a união entre negócios e sustentabilidade. Trata-se de uma estratégia de gerenciamento na qual a empresa avalia o impacto de suas ações do ponto de vista financeiro, social e ambiental. Assim, por essa definição, uma empresa consegue aplicar esse tipo de gestão, mudando seu foco completamente, o que trará benefícios futuros. De acordo com Oliveira et al. (2014), a partir do momento que a empresa se apropria da responsabilidade de aplicar no cotidiano da organização o conceito de gestão sustentável, ela se alia à questão do desenvolvimento econômico, socioeconômico e socioambiental.

Para Silva et al. (2018), atualmente as empresas observaram que não existem competição somente entre si, mas também ocorre uma espécie de cobrança para adoção de métodos e produtos socioambientais. Entretanto, sabemos que o custo de ser uma empresa socioambiental é elevado.

No caso da empresa em estudo, a economia de água favorece a desaceleração no caminho da escassez de água. Esse ato favorece a gestão ambiental da empresa,

RC: 102274

Disponível em:

https://www.nucleodoconhecimento.com.br/administracao/conscientizacaosocioambiental 
pois não há muito com o que se preocupar, visto que os produtos utilizados são biodegradáveis e os lixo é corretamente descartado.

Para Bettiol et al. (2017), a gestão ambiental se fez necessária nos últimos tempos com o avanço do aquecimento global. Por esse motivo, as organizações promovem a inserção de uma gestão ambiental para controlar as consequências das mudanças climáticas desse processo.

\subsection{ESTRATÉGIAS DE MARKETING}

O marketing é uma ferramenta de grande importância, é por meio dela que será feita a transmissão da visão da empresa para o público, dos serviços e produtos produzidos e como ela utiliza os recursos naturais em seus processos. Desta forma, a Ultraeco informa aos clientes qual o seu diferencial, mostrando que sua lavagem de veículos é um ponto de vantagem no mercado competitivo.

Conforme Marmo (2021), os benefícios de uma estratégia de marketing são inúmeros, visto que o objetivo do marketing é impulsionar o negócio. Quando se cria uma ação é necessário ter em mente o que será preciso para alcançar o sucesso da campanha. O primeiro passo é definir o público-alvo, entender suas necessidades e traçar uma estratégia.

É necessário que toda empresa tenha um plano de marketing e, com isso em mente, a Ultraeco, optou por implementar um marketing diferenciado, que fosse voltado para uma consciência inovadora, ou seja, o marketing verde. De acordo com Guimarães et al. (2015), o marketing verde tem toda a base do marketing tradicional e, junto com essa estrutura, também, tem a função de atender as necessidades das empresas que implementam ações sustentáveis em sua visão e missão.

Sem marketing não há vendas, sem vendas não há faturamento, sem faturamento não há negócio, e sem negócio não há propósito. Portanto, o desígnio da empresa está atrelado diretamente ao resultado. No caso da Ultraeco, encontrar um caminho

RC: 102274

Disponível em:

https://www.nucleodoconhecimento.com.br/administracao/conscientizacaosocioambiental 
inovador na lavagem de veículos transformou o negócio sustentável e lucrativo no propósito original da empresa.

\subsubsection{INBOUND MARKETING PARA CAPTAÇÃO E FIDELIZAÇÃO DE CLIENTES}

A Ultraeco está construindo sua credibilidade com o cliente a longo prazo, e se pode notar que a confiabilidade nos serviços é uma questão sensível, visto que o cliente ainda possui certo receio por não ter um conhecimento aprofundado a respeito da empresa.

O Marketing Inbound usa métodos que possibilitam o contato com o público-alvo de uma forma simples, direta e orgânica. Segundo Siqueira (2016), esse tipo de marketing dispõe de estratégias e métodos que tem como objetivo atrair clientes por meio de assuntos relevantes. O Inbound Marketing é uma ferramenta que conquista a atenção do futuro cliente, o que consequentemente faz com que o haja uma busca por parte do público ao em vez da empresa. Esse mecanismo de captação de cliente é uma forma moderna de utilizar as mídias sociais, proporcionando um aumento no alcance do cliente pela empresa e seus produtos, o que torna o processo diferenciado, se comparado com a forma tradicional do marketing empresarial. Esse tipo de atratividade é mensurado, e por meio dela se tem um controle do número de indivíduos que serão alcançados por uma determinada campanha. Deste modo, é possível compreender o que o cliente realmente necessita e corresponder a suas expectativas, por meio de um atendimento/produto personalizado.

Como aponta Menezes (2018), o foco não é atrelado a ser uma empresa prestadora de serviço que o entrega através de uma mão-de-obra impecável, mas captar e fidelizar o cliente através do conhecimento. $O$ Inbound traz esse benefício, pois a comunicação é feita por meio de blogs, podcasts, vídeo, e-Books, newsletters, whitepapers e outras formas de marketing, ocasionando alcance de uma gama variada de públicos-alvo.

RC: 102274

Disponível em:

https://www.nucleodoconhecimento.com.br/administracao/conscientizacaosocioambiental 
Segundo Costa et al. (2019), o Inbound Marketing trata-se de uma estratégia em que, ao invés da empresa ir atrás do cliente, ela se torna atrativa ao ponto de se tornar um ímã de clientes. Através do uso das redes sociais e outros meios de comunicação, a empresa comunica-se com o público de forma estratégica e orgânica, para atraí-los e torná-los clientes, fazendo com que se identifiquem com a empresa. Após o vínculo ser criado, a empresa trabalha em seu propósito junto ao cliente, para que ele compreenda a ideia que a ser transmitida e não apenas o serviço, conseguindo, dessa forma, fidelizar os clientes.

\subsubsection{O MARKETING COMO CONTRIBUINTE ESTRATÉGICO NO PROGRESSO ECOLÓGICO}

Como comentado anteriormente, utilizar o Inbound Marketing como estratégia de atração do cliente, por meio das plataformas de mídias sociais, para criar um vínculo mais abrangente com o público-alvo, é algo que exige um planejamento bem estruturado. De acordo com Silva (2016), para que o marketing esteja associado a estratégias de sustentabilidade é preciso englobar três tipos diferentes de marketing, são eles: marketing verde, marketing social e marketing crítico. O marketing verde é o desenvolvimento, criação e comercialização de produtos/serviços com uma pegada mais sustentável; o marketing social é focado no incentivo para se ter um comportamento preocupado com o lado sustentável; e por fim, o marketing crítico, estimula uma visão inovadora que tenha um viés sustentável.

Segundo Aquino (2020), há duas palavras que as pessoas relacionam a algo após ouvirem: Marketing e Ecológico. O marketing tem esse poder de transmitir ações de comunicação através da internet, divulgando e conquistando possíveis clientes. Mas, sabemos que o marketing, vai além de uma publicação visualmente bonita, ele é uma estratégia de eficiência e eficácia de divulgação dos processos.

RC: 102274

Disponível em:

https://www.nucleodoconhecimento.com.br/administracao/conscientizacao-

socioambiental 
No caso da Ultraeco, a cada serviço realizado há economia de recurso natural, portanto, a economia é proporcional à quantidade de serviços realizados e, consequentemente, a quantidade de vendas.

Para Nascimento (2017), o marketing poderia auxiliar apenas na venda de serviços da empresa. Entretanto, ao comunicar-se com o público a empresa busca um processo de conscientização a longo prazo, para que seja formada uma carteira de clientes que contribuam com o meio ambiente, o que é importante para qualquer empresa que esteja iniciando no mundo socioambiental.

\subsection{VISÃO E POLÍTICAS SOCIOAMBIENTAIS DA ULTRAECO}

Há mais de 10 anos, UltraEco se propôs a ser uma empresa socioambiental, após observar a necessidade de ingressar em um mercado diferente. $O$ fundador tinha em mente que, para inovar no ramo de sua escolha, era preciso encontrar formas alternativas de se realizar a lavagem dos carros, sem o consumo excessivo e com produtos que não poluíssem o meio ambiente. Com isso, sua visão e políticas estavam atreladas à questão socioambiental. $O$ objetivo era ser exemplo na qualidade de lavagem, limpeza e conservação de veículos, com o foco na sustentabilidade e economia de água.

\subsubsection{O ENDOMARKETING NA PROMOÇÃO DE UMA VISÃO E POLÍTICA SOCIOAMBIENTAL A LONGO PRAZO}

O endomarketing é importante porque ajuda a empresa a ter uma relação com seus colaboradores de forma objetiva, clara e direta. A visão da Ultraeco, é "ser referencial em qualidade de lavagem, limpeza, e conservação de veículos, sempre com foco na sustentabilidade e economia de água". Tento esse referencial de proposta, é preciso que todos os colaboradores conheçam este objetivo e o implementem em suas ações.

RC: 102274

Disponível em:

https://www.nucleodoconhecimento.com.br/administracao/conscientizacaosocioambiental 
De acordo com Silva (2013), o endomarketing é um mecanismo que facilita a comunicação entre os gestores e seu grupo de colaboradores, o que diminui a tensão hierárquica e abre caminho para uma comunicação ampla e motivacional. Esse marketing tem a função de adaptar estratégica que o marketing tradicional aplicava, mas com uma visão moderna e que se preocupa com o desempenho interno.

Como proposto por Araújo (2018), o endomarketing é uma tática voltada para o público interno da empresa, com o foco em não haver diferenças entre os colaboradores, tornando o contato entre os setores mais fácil. Os colaboradores precisam "vestir a camisa" do negócio, para que, assim, a empresa tenha um desenvolvimento melhor. $\mathrm{O}$ endomarketing é um mecanismo de melhoria para que 0 negócio se torne um instrumento importante, com o objetivo de proporcionar a harmonia entre a equipe.

O endomarketing é uma ótima ferramenta para gestores visam uma equipe bem estruturada. De acordo Froemming (2017), o objetivo de envolver os colaboradores no negócio gera mais motivação e melhora a produtividade, principalmente, em equipes e entre setores, conquistando mais clientes satisfeitos.

\subsubsection{VERIFICAR SE A FILOSOFIA DA ULTRAECO TEM SIDO ABSORVIDA E INSERIDA NO COTIDIANO DOS COLABORADORES}

A cultura organizacional de uma empresa é algo importante. De acordo com Wentz e Froehlich (2012), a cultura organizacional é construída por meio da junção dos valores do fundador com a agregação dos colaboradores. Com isso, se tem o conjunto de valores e políticas da organização, deixando de ser somente do fundador. É a partir dessa transformação que haverá o compartilhamento interno e, com isso, o direcionamento para o alcance dos objetivos centrais da empresa.

RC: 102274

Disponível em:

https://www.nucleodoconhecimento.com.br/administracao/conscientizacaosocioambiental 
Segundo Fonseca et al. (2018), muitas pessoas citam a filosofia de uma empresa ou a cultura organizacional, mas poucos sabem, realmente, qual a importância dessa pequena frase na construção de uma empresa firme.

Para Larentis et al. (2017), a cultura de uma sociedade tem seu padrão, e não é diferente dentro de uma empresa. A cultura do negócio trabalha com um modelo de atitudes e pensamentos para os colaboradores.

Para Ultraeco, observamos que o fundador e a cultura andam juntos. A cultura da empresa é ajustada sempre que uma pessoa entra na equipe, mas no final, quem diz para onde a organização está indo são os de maior influência, os que têm visão do futuro.

\subsubsection{VANTAGENS E DESVANTAGENS DO ENDOMARKETING}

O endomarketing, como abordado antes, é um método que pode ser implementado numa empresa, visto que tem inúmeras vantagens. Porém, tudo tem seu lado positivo e negativo. Nesse tópico, iremos discutir sobre esses fatores e demonstrar porque vale a pena inserir na sua empresa essa técnica.

Segundo Santos (2013), o foco do endomarketing é atribuir valor ao colaborador. O diferencial desse tipo de marketing é a importância que a empresa tem em relação a opinião e ideias que o colaborador pode agregar para contribuir com a evolução empresarial. Porém, existem empresas que permanecem sem perspectiva de incluir esse tipo de marketing em suas estratégias internas, pois acreditam que esse método de atração custará tempo excessivo e desperdiçará recursos.

Segundo Souza et al. (2019), investir na empresa não é somente trazer as melhores ferramentas, mas sim as necessárias. O endomarketing também tem suas desvantagens, como o alto investimento feito em treinamento e bonificação, tendo em mente o conforto do colaborador. Porém, é necessário deixar claro que, mesmo com essas desvantagens, esses métodos ainda proporcionam ótimos resultados.

RC: 102274

Disponível em:

https://www.nucleodoconhecimento.com.br/administracao/conscientizacao-

socioambiental 


\subsection{PLANEJAMENTO DE INVESTIMENTOS}

Ter um plano de investimento traz vários benefícios como: visualização dos objetivos de uma forma mais clara, compreensão de quais investimentos combinam com o perfil da empresa, criação de um orçamento para aplicação, e até a estipulação de um prazo para o alcance dos objetivos. De acordo com Andrade et al. (2018), o plano de investimentos tem que ser bem estruturado para que haja um constante mecanismo de pesquisa, implementação de novas técnicas e materiais a serem utilizados nos procedimentos de serviços/produtos.

Segundo Cunha e Samanez (2014), ultimamente, a sustentabilidade tem sido implementada na visão das empresas, o que contribuiu para a entrada desse ramo nos setores de investimentos e mercado de capitais. Essa mudança na gestão empresarial ocasionou diversos impactos na forma como isso seria inserido na bolsa de valores, criando, assim, uma nova forma de investimento, ou seja, o investimento sustentável, conhecido também como IS. Seu principal objetivo é incluir as preocupações ambientais no momento do investimento, salientando os impactos socioambientais.

\subsubsection{CATEGORIAS DE INVESTIMENTOS}

Para as empresas, o mais importante é ter conhecimento a respeito tipos de investimentos necessários para que suas aplicações monetárias sejam realizadas de forma a trazer resultados lucrativos a empresa. Segundo Bachur (2021), o empreendedor deve ter em mente que a ideia de um possível negócio precisa de uma base econômica no qual seja viável investir. É necessário, portanto, ter em mente que será preciso analisar o investimento mais rentável e o momento mais propício para investir.

Como apontam Siqueira et al. (2017), investir em um negócio não é fácil, mas requer conhecimento e planejamento. O mercado de investimentos está aumentando em

RC: 102274

Disponível em:

https://www.nucleodoconhecimento.com.br/administracao/conscientizacaosocioambiental 
relação ao socioambiental, as empresas estão vendo a importância e a necessidade dessa aplicação.

Não existe investimento sem risco. Quando a empresa Ultraeco resolveu investir na lavagem ecológica, ela estava ciente dos riscos. Os futuros clientes não teriam tanta confiança por falta de conhecimento referente ao produto e o processo, entre outras dúvidas que se tornaria risco para a empresa.

Segundo Gomes (2019), investir requer análise, principalmente quando se trata de uma empresa. Primeiro é preciso ter um objetivo, analisar toda situação financeira e verificar como o mercado está reagindo perante a situação. Na balança da análise, é bom lembrar que tudo é levado em conta, desde o capital que a empresa possui até o que ela está disposta a arriscar.

\subsubsection{BUSCA POR INOVAÇÃO EM PRODUTOS BIODEGRADÁVEIS E ECOLÓGICOS}

De acordo com Ruwer (2013), quando pensamos na sustentabilidade é preciso ter em mente que estamos em uma época em que os indivíduos têm uma consciência maior com relação a preservar o meio ambiente e exigem que as empresas, ao produzirem algum produto ou ofertarem algum serviço, ajam da forma mais correta possível e com o mínimo de agressão ao meio ambiente. A Ultraeco, buscou implementar essa ideia em seus processos.

O assunto, produto biodegradável, tem ganhado atenção, principalmente no que diz respeito a implementação nas linhas de produção das empresas. Para Lobo (2018), os produtos biodegradáveis vêm ganhando seu valor com o tempo, e uma parte da população vem se conscientizando dessa importância. São chamados de biodegradáveis por serem feitos a partir de material orgânico e por terem facilidade em se decompor, causando pequeno impacto na biosfera e, assim, reduzindo o impacto da poluição das cidades.

RC: 102274

Disponível em:

https://www.nucleodoconhecimento.com.br/administracao/conscientizacaosocioambiental 
Como aponta Chagas et al. (2019), os produtos que são legalmente comprovados como biodegradáveis apresentam decomposição mais rápida em relação a outros produtos e sua absorção pela natureza não gera impacto algum. Por meio da análise do rótulo é possível descobrir se um produto é biodegradável e se sua fabricação foi feita de modo a não produzir excesso de poluição.

\subsubsection{VALOR DA APLICABILIDADE ERP PARA OS PLANOS DE INVESTIMENTOS}

De acordo com Souza (2014), o programa de aplicabilidade ERP tem o intuito de tornar a empresa mais unificada tecnologicamente partindo da ideia de que todos os departamentos estariam em um único sistema que atendesse todas as necessidades particulares de cada setor. Isso traria uma capacidade vasta de processos operacionais, o que facilitaria estratégias de investimentos e planos de ação em busca de novos métodos.

Para Basílio et al. (2019), vários gestores ainda não conhecem a ferramenta ERP. Através dela, o gestor tem um foco mais preciso a fim de elevar o crescimento e a lucratividade da empresa. O ERP implementa a competência da gestão e dá velocidade aos procedimentos, e por conta disso, o diálogo entre as equipes, passa a ser mais real e os problemas podem ser resolvidos com rapidez.

Segundo Mezzalira (2017), em um cenário de grande competitividade, o ERP, é um bom investimento a se fazer. O movimento dos processos da empresa permite programação e aplicação mais exatas, baseadas em dados, não em sugestão, no sistema ERP (sistema de gestão empresarial).

\section{MATERIAIS E MÉTODOS}

Metodologia é uma palavra derivada de "método", do Latim "methodus", cujo significado é "caminho ou a via para a realização de algo". Segundo Santos (2016, p. 106), "método pode ser conceituado como regra, norma, busca da verdade,

RC: 102274

Disponível em:

https://www.nucleodoconhecimento.com.br/administracao/conscientizacaosocioambiental 
detecção de erros na tentativa de alcançar um objetivo desejado". A partir desse pressuposto, podemos afirmar que o método é de suma importância, proporcionando economia de tempo, de recursos, e fornecendo segurança na ação, para alcance do resultado planejado.

\subsection{PROCEDIMENTOS METODOLÓGICOS}

O método utilizado na pesquisa foi o dedutivo, suas principais fases se dividem em: evidências, análise, síntese e enumeração. "Na dedução, o raciocínio parte de uma premissa geral para o particular." (ZANELLA, 2013, p. 21)

Através de entrevista com o proprietário da empresa Ultraeco Manaus, possibilitouse a coleta de dados para este estudo. Depois, foi realizada a análise e interpretação, e, por fim, enumeramos as informações sintetizadas de forma que facilitasse o processo de tomada de decisão, focando nos pontos fracos que precisam ser melhorados.

\subsubsection{QUANTO À NATUREZA}

A natureza é classificada como qualitativa. Neste tipo de pesquisa "[...] a interpretação do pesquisador apresenta uma importância fundamental. [..] não se trata apenas de um conjunto de informações fechadas cujo valor numérico é o único aspecto a ser levado em consideração." (MENEZES et al., 2019, p. 29). Para estudar esse problema, os pesquisadores usam uma abordagem qualitativa de investigação, ou seja, uma coleta de dados em um contexto natural e sensível às pessoas e ao ambiente de estudo. A análise de dados é tanto indutiva quanto dedutiva, e estabelece padrões ou temas. O relatório final ou a apresentação incluem as vozes dos participantes, a reflexão do pesquisador, uma descrição complexa, a interpretação do problema, a sua contribuição para a literatura ou um apontamento para uma mudança.

RC: 102274

Disponível em:

https://www.nucleodoconhecimento.com.br/administracao/conscientizacaosocioambiental 
$\mathrm{Na}$ Ultraeco, foi realizada uma pesquisa qualitativa com base nas informações cedidas pelo CEO da empresa. Foi executada uma coleta de dados com uma ótica sensível, pensando no viés do colaborador, mas com um olhar que engloba o meio ambiente e as ações da organização. Visto que a empresa tem um enfoque maior na causa ambiental.

\subsubsection{QUANTO AOS FINS}

No caso da empresa estudada, o objetivo geral é definir uma estratégia sustentável que esteja atrelada à redução do consumo de água e em como isso contribui para que a Ultraeco tenha visibilidade no seu negócio.

De acordo com Filho (2018):

[...] a ação de justificar a pesquisa depende, em parte, da reafirmação dos objetivos da proposta, como se houvesse uma concepção subjacente a dizer que o fato de haver objetivos, algo a ser alcançado ao final da ação de investigação, atestasse que a pesquisa é justificável (FILHO, 2018, p. 149).

\subsubsection{QUANTO AOS MEIOS}

O tipo de abordagem utilizada para a coleta de dados foi a pesquisa de campo, ou seja, através de observação, coleta (podendo ser feita por entrevistas e questionários), análise das informações obtidas e interpretação.

De acordo com Aragão et al. (2017):

Os procedimentos e técnicas adequadas ao desenvolvimento da pesquisa estão diretamente ligados tanto ao problema de pesquisa criado a partir do tema, quanto à consecução dos objetivos específicos que irão embasar as análises e interpretação dos resultados obtidos na pesquisa de campo (ARAGÃO et al., 2017, p. 34-35).

Conforme realizamos entrevistas e pesquisas em livros, foram obtidas informações suficientes para concluir os objetivos intermediários, e, com isso, alcançar o objetivo

RC: 102274

Disponível em:

https://www.nucleodoconhecimento.com.br/administracao/conscientizacaosocioambiental 
geral, sempre pensando na questão da sustentabilidade e como isso poderia agregar um diferencial para os procedimentos e produtos da empresa Ultraeco.

\subsection{CARACTERÍSTICAS DA EMPRESA}

A Ultraeco Manaus é uma empresa de pequeno porte no ramo de lavagem ecológica de veículos, que trabalha com atendimentos locais e Delivery. Atende desde pessoas físicas a empresas grandes com frotas. Utiliza produtos sustentáveis durante seus processos e, por esse motivo, se destaca no mercado de lavagem automotiva, oferecendo um serviço de qualidade.

Oferecendo lavagens desde carros pequenos até caminhões, a Ultraeco conta com uma gama de serviços diferenciados. Entre seus serviços estão a lavagem ecológica simples, enceramentos, polimentos, limpeza de motor e higienização de veículos de todos os tipos e tamanhos. Apesar do pequeno porte, é uma empresa com grande potencial de crescimento, devido a seu feito na economia de recursos naturais.

\section{RESULTADOS E DISCUSSÕES}

Após os estudos realizados na etapa do Diagnóstico Organizacional, foi observado que a empresa em questão tem pontos essenciais em cada área funcional da organização, como é possível de notar no Gráfico 01: Média - Desempenho por Área Funcional.

RC: 102274

Disponível em:

https://www.nucleodoconhecimento.com.br/administracao/conscientizacaosocioambiental 
Gráfico 01: Média - Desempenho por Área Funcional.

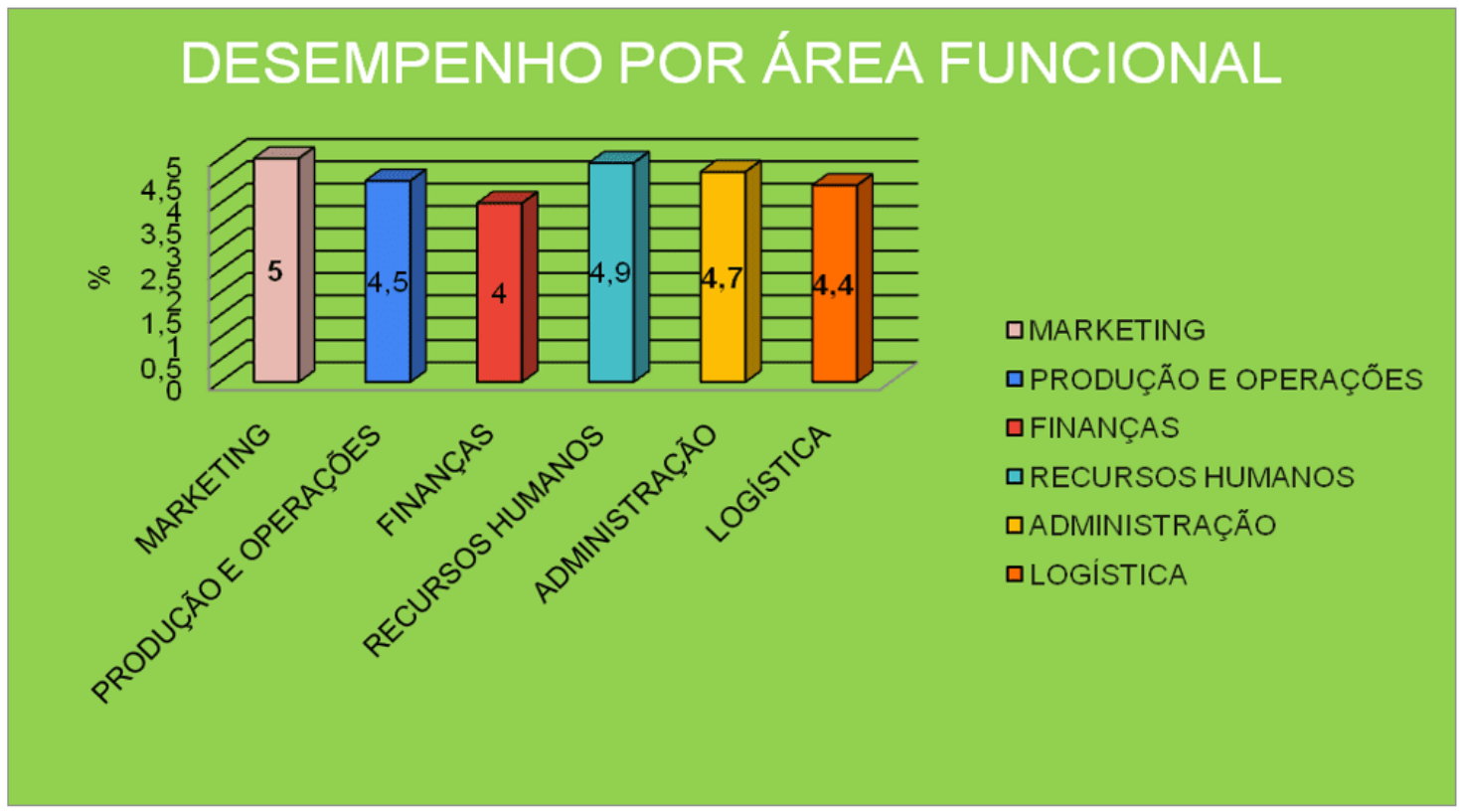

Fonte: Elaborado pelos autores com base na coleta de dados (2021)

Foi verificado que a Ultraeco tem a área de Marketing e recursos humanos como as que possuem a melhor performance. Operação, Administração e Logística são áreas de desempenho médio. Por fim, o setor de Finanças é apresentado como a área com menor desempenho, como se mostra a seguir.

Quadro 01: Finanças

\begin{tabular}{|l|l|l|l|l|l|l|}
\hline FATORES CRÍTICOS & 5 & 4 & 3 & 2 & 1 \\
\hline 1 & $\begin{array}{l}\text { Constatou-se que os donos possuem conhecimento } \\
\text { genuíno da definição de faturamento }\end{array}$ & $\mathrm{X}$ & & & \\
\hline 2 & $\begin{array}{l}\text { Averiguou-se que os administradores reconhecem a } \\
\text { rentabilidade da empresa }\end{array}$ & & $\mathrm{X}$ & & \\
\hline 3 & $\begin{array}{l}\text { Nota-se que existe investimento mensal para que o } \\
\text { giro de estoque esteja sempre movimentado }\end{array}$ & & $\mathrm{X}$ & \\
\hline 4 & Destacou-se que os sócios investem continuamente & & $\mathrm{X}$ & \\
\hline
\end{tabular}

RC: 102274

Disponível em:

https://www.nucleodoconhecimento.com.br/administracao/conscientizacaosocioambiental 


\begin{tabular}{|l|l|l|l|l|l|}
\hline & para gerar a liquidez dos seus recursos & & & \\
\hline 5 & $\begin{array}{l}\text { Identificou-se que a Contabilidade é utilizada como um } \\
\text { instrumento de gestão }\end{array}$ & & & \\
\hline 6 & $\begin{array}{l}\text { Salienta-se que a empresa preza pela sua capacidade } \\
\text { de pagamento, honrando suas dívidas }\end{array}$ & $X$ & & \\
\hline 7 & $\begin{array}{l}\text { Verificou-se que a empresa utilize os demonstrativos } \\
\text { financeiros nas tomadas de decisões }\end{array}$ & & & \\
\hline 8 & $\begin{array}{l}\text { Observou-se que há determinação técnica dos preços } \\
\text { de venda e faturamento pretendidos }\end{array}$ & $X$ & & & \\
\hline 9 & $\begin{array}{l}\text { Nota-se que a empresa possui uma avaliação contínua } \\
\text { de sua Gestão de Riscos }\end{array}$ & $X$ & & & \\
\hline 10 & $\begin{array}{l}\text { Constatou-se que o negócio se mostra viável } \\
\text { financeiramente }\end{array}$ & $X$ & & & \\
\hline TOTAL ( $\Sigma$ ) & 25 & 4 & 9 & 2 & 0 \\
\hline MÉDIA POR GRAU (POR COLUNA) & 2,5 & 0,4 & 0,9 & 0,2 & 0 \\
\hline DESEMPENHO DA ÁREA & 0 & & \\
\hline
\end{tabular}

*Sendo 5 valor máximo (ponto muito forte) e 1 valor mínimo (ponto muito fraco).

Fonte: Elaborado pelos autores com base na coleta de dados (2021)

Como podemos observar no quadro 01 , verificou-se pontos fundamentais na área de faturamento da empresa Ultraeco, os quais têm grande importância para a sustentabilidade e a efetividade do negócio. Neste contexto, é essencial que seus colaboradores tenham instruções bem estabelecidas e contem com padrões determinados para alcançar seus objetivos. Desta forma, o problema da pesquisa é: como a implementação de ações sustentáveis podem colaborar como estratégia de marketing para captação de clientes?

RC: 102274

Disponível em:

https://www.nucleodoconhecimento.com.br/administracao/conscientizacaosocioambiental 


\subsection{PLANEJAMENTO DE AÇÕES}

A construção das ações interventivas é uma tática que considera certas práticas para o alcance dos objetivos propostos na empresa. O grupo de ações apresentadas no quadro 2 tem em vista tornar a empresa mais comunicativa, atrativa, e, sobretudo, se fazer presente na mente do consumidor.

Quadro 02: Ações interventivas Ultraeco

\begin{tabular}{|l|l|l|l|l|}
\hline & Ações Interventivas & Cronologia & Duração & Custo \\
\hline 1 & $\begin{array}{l}\text { Gerar relatórios dos impactos na redução } \\
\text { de consumo de recursos naturais (Água). }\end{array}$ & setembro & 15 dias & $\mathrm{R} \$$ \\
\hline 2 & $\begin{array}{l}\text { Criar um plano de marketing para } \\
\text { divulgação dos resultados ambientais com } \\
\text { forma de captação de clientes. }\end{array}$ & setembro & $\begin{array}{l}\text { A cada 15 } \\
\text { dias }\end{array}$ & $\begin{array}{l}\mathrm{R} \$ \\
1.200,00\end{array}$ \\
\hline 3 & $\begin{array}{l}\text { Divulgar através do endomarketing a visão } \\
\text { e políticas ambientais da empresa. }\end{array}$ & Outubro & Diária & $\mathrm{R} \$$ \\
\hline 4 & $\begin{array}{l}\text { Elaborar planos de investimentos mensais } \\
\text { que visam manter as práticas operacionais } \\
\text { sustentáveis. }\end{array}$ & Mensal & $\begin{array}{l}1 \text { vez ao } \\
\text { mês }\end{array}$ & $\begin{array}{l}\mathrm{R} \$ \\
2.000,00\end{array}$ \\
\hline
\end{tabular}

Fonte: Elaborado pelos autores com base na coleta de dados (2021).

A sugestão de solução de cada etapa se fortaleceu por meio de quadros $5 \mathrm{w} 2 \mathrm{~h}$, que é uma ferramenta de qualidade utilizada para reconhecer as ações e responsabilidades do andamento dos procedimentos, visando responder a quatro das ações interventivas fundamentais. Tendo sempre em foco uma estratégia que seja simples, eficiente e eficaz, ou seja, através da sua estrutura: Whats (o que seria feito); Why (porque seria feito); Where (onde foi feito); When (quando será feito); Who (porque seria feito); How (como seria feito) e How Much (quanto custará fazer).

RC: 102274

Disponível em:

https://www.nucleodoconhecimento.com.br/administracao/conscientizacaosocioambiental 


\subsubsection{GERAR RELATÓRIOS DOS IMPACTOS NA REDUÇÃO DE CONSUMO DE RECURSOS NATURAIS (ÁGUA)}

A preocupação com o cuidado dos recursos naturais é cada vez maior, entretanto, ainda há um caminho longo a se percorrer até que se feche um acordo sustentável que realmente seja um bom negócio tanto para as empresas como para o meio ambiente.

Quadro 03: 5w2h - Gerar relatórios dos impactos na redução de consumo de recursos naturais (Água)

Gerar relatórios dos impactos na redução de consumo de recursos naturais (Água)

O que? Redução de consumo de recursos naturais.

Por quê? Para que os recursos naturais sejam utilizados de uma forma mais sustentável e inteligente.

Onde? Na empresa.

Quando? Setembro.

Quem? Sócios e afiliados.

Como? Por meio de reuniões para aperfeiçoar e analisar novas estratégias que o mercado oferece diante de tanta inovação.

\section{Quanto? R $\$ 900,00$}

Fonte: Elaborado pelos autores com base na coleta de dados (2021)

No quadro 03, concluiu-se que é necessário estimular o conhecimento e discutir a respeito de como os recursos naturais devem ser utilizados, além de outros fatores que ajudam a entender a importância desse consumo, em um tempo em que as empresas estão em constante transformação e se tornando mais sustentáveis. Apesar de ser um investimento um pouco excessivo para algumas companhias, ter a vantagem de constantemente eliminar o desperdício é algo cada vez mais básico

RC: 102274

Disponível em:

https://www.nucleodoconhecimento.com.br/administracao/conscientizacaosocioambiental 
nas empresas. Para a empresa Ultraeco, aplicou-se um processo de baixa utilização de água que foi capaz de garantir que a empresa tenha uma pegada mais ecológica.

\subsubsection{CRIAR UM PLANO DE MARKETING PARA DIVULGAÇÃO DOS RESULTADOS AMBIENTAIS COM FORMA DE CAPTAÇÃO DE CLIENTES}

No cenário atual em que vivemos, o objetivo é entender o uso abusivo da água e apresentar soluções a esse obstáculo. Sabemos que esse recurso é um elemento indispensável no desenvolvimento e no progresso ambiental. Com essa preocupação, a empresa se viu na obrigação de expandir mais o seu negócio, visto que um dos objetivos da empresa se tratava do combate a esse desperdício.

Quadro 04: 5w2h - Criar um plano de marketing para divulgação dos resultados ambientais com forma de captação de clientes

Criar um plano de marketing para divulgação dos resultados ambientais com forma de captação de clientes.

O que? Definir plano estratégico de marketing através de resultados ambientais, conquistando clientes.

Por quê? Para um melhor desenvolvimento ecológico.

Onde? Na empresa.

Quando? A cada 15 dias.

Quem? Departamento de marketing.

Como? Por meio de análises e de seu conhecimento já estudando pelos colaboradores.

Quanto? $R \$ 1.200,00$

Fonte: Elaborado pelos autores com base na coleta de dados (2021)

RC: 102274

Disponível em:

https://www.nucleodoconhecimento.com.br/administracao/conscientizacaosocioambiental 
De acordo com quadro 04, a intenção era utilizar a estratégia do marketing, em razão da agilidade. O marketing vem tomando conta dos meios de divulgação de produtos e serviços e por isso se tornou, nessa empresa, uma ótima forma de transmitir ao público todos os benefícios e vantagens de uma lavagem ecológica. Com esta ação, esperava-se que a empresa pudesse atrair o interesse de um nicho de clientes que se preocupavam com ações sustentáveis e, por conseguinte, buscavam o aumento da captação de clientes.

\subsubsection{DIVULGAR ATRAVÉS DO ENDOMARKETING A VISÃO E POLÍTICAS AMBIENTAIS DA EMPRESA}

endomarketing nada mais é do que um marketing interno voltado e focado em ações para colaboradores. A ideia por trás dessa metodologia é demonstrar a preocupação que a empresa possui em relação ao meio ambiente e incentivar que seus colaboradores também desenvolvam a mesma preocupação, o que, consequentemente, transparecerá aos clientes e deixará claro o diferencial da empresa.

O plano de ação se deu por meio da implantação de campanhas de divulgação a respeito das políticas e da visão socioambiental que a empresa estabeleceu e utilizou para guiar suas ações internas e externas. A partir disso, foi criado o código de ética e conduta para que a sustentabilidade dentro da empresa se mantivesse constante. Nesse manual, constava a missão, a visão e os valores que a empresa possui em sua trajetória com produtos biodegradáveis; aos produtos/serviços ofertados aos clientes; e à sua estratégia socioambiental.

Quadro 05: 5w2h - Divulgar através do endomarketing a visão e políticas ambientais da empresa

Divulgar através do endomarketing a visão e políticas ambientais da empresa.

O que? Realização de planos de endomarketing para que os colaboradores

RC: 102274

Disponível em:

https://www.nucleodoconhecimento.com.br/administracao/conscientizacaosocioambiental 
tenham um entendimento da gestão socioambiental da empresa, e cada vez mais incorpore em seu dia a dia.

Por quê? É importante que todos os colaboradores da empresa tenham o conhecimento do que a empresa transparece para os clientes e quais são seus focos para o futuro. E o que ela está fazendo para ter o viés da sustentabilidade.

Onde? Na empresa.

Quando? Outubro.

Quem? Departamento de Comunicação e Marketing.

Como? Através de campanhas de conscientização e de um minilivro que aborda, tudo sobre a empresa e sua gestão sustentável.

Quanto? $R \$ 1.500,00$

Fonte: Elaborado pelos autores com base na coleta de dados (2021)

De acordo com quadro 05, podemos chegar à conclusão de que o resultado das reuniões gerou os planos de investimentos, o que permitiu que as pesquisas fossem realizadas. A partir dessa etapa, houve a implementação de propostas que tinham como foco a sustentabilidade e que, com isso, gerou-se cada vez mais credibilidade e fidelização do cliente.

Esta ação teve o objetivo de promover a conscientização ecológica dos colaboradores da empresa, buscando uma uniformidade de pensamento e o sentimento de pertencimento ao projeto.

\subsubsection{ELABORAR PLANOS DE INVESTIMENTOS MENSAIS QUE VISAM MANTER AS PRÁTICAS OPERACIONAIS SUSTENTÁVEIS}

A empresa Ultraeco tem uma proposta de lavagem ecológica de veículos que se difere do restante de seu nicho. Ter um plano de investimento foi essencial para que a empresa continue em constante inovação e, assim, conseguisse demonstrar aos

RC: 102274

Disponível em:

https://www.nucleodoconhecimento.com.br/administracao/conscientizacaosocioambiental 
clientes que ela possui uma vantagem que outras não possuem, que é a lavagem sem a utilização abundante de água. Visto isso, é importante sempre ter em mente que inovar e buscar algo revolucionário, com foco no sustentável, é inevitável.

Quadro 06: 5w2h - Elaborar planos de investimentos mensais que visam manter as práticas operacionais sustentáveis

Elaborar planos de investimentos mensais que visam manter as práticas operacionais sustentáveis.

O que? Definir planos de investimentos.

Por quê? Para que a empresa tenha uma constante em procedimentos e produtos inovadores para manter a linha socioambiental.

Onde? Na empresa.

Quando? 1 vez ao mês.

Quem? Setor financeiro e contábil.

Como? Através de reunião para formular planos de investimentos que será projetado uma ação mensal que visa separar uma parte de lucro e distribuir para pesquisas em propostas sustentáveis e que possa ser aplicado na empresa Ultraeco.

Quanto? $R \$ 2.000,00$

Fonte: Elaborado pelos autores com base na coleta de dados (2021)

No quadro 06, se pode observar a introdução de um cronograma mensal de investimentos em pesquisas focadas em inovações sustentáveis. A partir dessas pesquisas, houve a implementação de ações com base em propostas que tinham foco na sustentabilidade e, que, com isso, gerou-se cada vez mais credibilidade e fidelização do cliente com a Ultraeco.

RC: 102274

Disponível em:

https://www.nucleodoconhecimento.com.br/administracao/conscientizacaosocioambiental 


\section{CONSIDERAÇÕES FINAIS}

O estudo do artigo teve como premissa básica estudar uma empresa que age por meio de ações voltadas para o socioambiental. Dentro dessas especificações, se identificou a empresa Ultraeco. Por meio de uma análise inicial realizada na empresa, levantou-se a seguinte pergunta pesquisa: Como a implementação de ações sustentáveis podem colaborar como estratégia de marketing para captação de clientes? Como resposta, concluímos que, a introdução de investimentos em práticas operacionais sustentáveis inovadoras; a utilização o endomarketing para consolidar as práticas sustentáveis no ambiente interno da organização; a produção de relatórios dos impactos de redução de recursos naturais com o estabelecimento um plano de divulgação das práticas sustentáveis da organização, buscando consolidar a captação de nicho de clientes que optam por consumir produtos e serviços de empresas que praticam conceitos sustentáveis, é possível estabelecer estratégias que auxiliem na captação de clientes.

O objetivo deste artigo foi atingido no sentido de construir um conjunto de ações interventivas, que tinham como foco principal responder à questão norteadora da pesquisa, utilizando estratégias de marketing para conscientização das equipes internas e captação de clientes do nicho de mercado que buscava parcerias com empresas que permeiem suas ações por questões sustentáveis. A redução de recursos naturais, gestão sustentável e iniciativas que podem afetar o desempenho financeiro das empresas demonstraram a preocupação da empresa com os recursos naturais e o interesse no conceito de lavagem ecológica surgiu como consequência. As empresas que estão inseridas no mercado têm sido incentivadas a explorarem esse ramo, e, assim, desenvolvem-se cada vez mais para que 0 nicho socioambiental cresça cada dia mais.

Por fim, compreendeu-se que as propostas do artigo foram atendidas, no sentido de que se criou um conjunto de ações interventivas que direcionam a empresa aos resultados propostos de acordo com a questão norteadora.

RC: 102274

Disponível em:

https://www.nucleodoconhecimento.com.br/administracao/conscientizacao-

socioambiental 
Por fim, compreendeu-se que as propostas do artigo foram atendidas, no sentido de que se criou um conjunto de ações interventivas que direcionam a empresa aos resultados propostos de acordo com a questão norteadora. Esperava-se ter um nível de satisfação elevado, pois o foco é a questão da sustentabilidade que a empresa agregava em seu cotidiano, mas que precisa ser explorada de uma forma mais aprofundada para que seus resultados pudessem ser divulgados, influenciando tanto os clientes como os funcionários a desenvolverem a consciência de que a empresa se destaca por ofertar um serviço que a concorrência não fornece. Conclui-se que o mercado sustentável ainda está em crescimento, visto que muitas empresas apresentam um déficit nessa questão, porém, é fundamental que a sociedade apresente posicionamento e engajamento em relação a esse assunto. A esse respeito, este artigo proporcionou um legado fundamentado para futuras pesquisas acadêmicas, sobretudo para os empresários do setor e para sociedade em geral.

\section{REFERÊNCIAS}

ANDRADE, E. C.; FORTES, R. M. B. Benefícios do Planejamento colaborativo de demanda por meio de operador logístico em rede de restaurantes fast food. Revista Oswaldo $\quad$ Cruz, 2013.2 Disponível em:http://revista.oswaldocruz.br/Content/pdf/Edicao_16_ANDRADE_Elisangela_Cris tina.pdf. Acessado em: 27 set. 2021.

AQUINO, F. Convocações ecológicas: o meio ambiente nas campanhas presidenciais brasileiras. Revista da Faculdade de Letras da Universidade do Porto, $\quad$ p. $\quad 75-94, \quad 2020 . \quad$ Disponível em: https://ojs.letras.up.pt/index.php/Sociologia/article/view/10277/9356. Acessado em: 05 set. 2021.

ARAÚJO, S. do N. Endomarketing como Ferramenta para melhorar a satisfação dos colaboradores da Ideal Peças LTDA. 2018. Dissertação (MBA em Gestão de Pessoas) - Universitário de João Pessoa - UNIPÊ, Campina Grande, PB, 2018.

RC: 102274

Disponível em:

https://www.nucleodoconhecimento.com.br/administracao/conscientizacaosocioambiental 
ARAGÃO, J. W. M. de; MENDES NETA, M. A. H. Metodologia científica. Salvador: UFBA, 2017.

AZEVEDO, D. Revisão de Literatura, Referencial Teórico, Fundamentação Teórica e Framework Conceitual em Pesquisa - diferenças e propósitos. WorkingPaper, $2016 . \quad$ Disponível em: https://unisinos.academia.edu/DeboraAzevedo/Papers. Acesso em: 27 set. 2021.

BACHUR, P. Principais Tipos de Investimentos Empresariais: espécies e atuações. Site EJUR, 28 jan. 2021. Disponível em: https://ejur.com.br/blog/principais-tipos-de-investimentos-empresariais-especies-eatuacoes/. Acessado em: 04 set. 2021.

BASILIO, C. H. et al. Sistemas Integrados de Gestão Empresarial - ERP. Revista Pesquisa e Ação, v. $5, \quad \mathrm{n} \quad$.3, 2019. Disponível em: https://revistas.brazcubas.br/index.php/pesquisa/issue/view/78. Acessado em: 06 set. 2021.

BETTIOL, W. et al. Aquecimento global e problemas fitossanitários. Brasília, DF: Embrapa, 2017.

BOTH, F.; FISCHER, A. Gestão e Contabilidade Ambiental. Unoesc \&Amp; Ciência - ACSA, Santa Catarina, v. 8, n. 1, pp. 49-58, 2017. Disponível em: $<$ https://portalperiodicos.unoesc.edu.br/acsa/article/view/12599>. Acesso em: 27 set. 2021.

CHAGAS, G. M. de O.; OLIVEIRA, V. M. de; CORREIA, S. É. N. Comportamento de Consumo de Produtos com Apelo Ecológico: um levantamento com os alunos da UFCG/PB. Revista Reuna, Belo Horizonte, v. 24, n. 4, p. 65-83, 2019. Disponível em: https://revistas.una.br/reuna/article/view/970. Acessado em: 03 set. 2021.

RC: 102274

Disponível em:

https://www.nucleodoconhecimento.com.br/administracao/conscientizacao-

socioambiental 
CostA, T. C.; FERREIRA, M. P. CUNHA, J. A. C. da; PINTO, C. F. Como as Capacidades de Marketing Determinam a Escolha dos Modos de Entrada no Estrangeiro e a Seleção dos Países de Destino. Revista Eletrônica de Negócios Internacionais (Internext), v. 15, n. 1, p. 53-70, 2020. Disponível em: https://www.redalyc.org/articulo.oa?id=557563980004. Acessado em: 04 set. 2021.

CUNHA, F. A. F. de S.; SAMANEZ, C. P. Análise de desempenho dos investimentos sustentáveis no mercado acionário brasileiro. Production, Rio de Janeiro, v. 24, n. 2, p. 420-434, 2014. Disponível em: https://www.researchgate.net/publication/307850489_Analise_de_desempenho_dos _investimentos_sustentaveis_no_mercado_acionario_brasileiro. Acessado em: 26 set. 2021.

FILHO, D. P. de S. Reutilização de Água Residual no Processo de Gestão de Lava Jato: um estudo de multi caso. 2017. Monografia (Mestrado em Engenharia de Produção) - Programa de Pós-Graduação em Engenharia de Produção, Universidade Federal do Amazonas, Manaus, AM, 2017.

FILHO, F. A. Como mestrandos agem retoricamente quando precisam justificar suas pesquisas. Revista Brasileira de Linguística Aplicada - RBLA, Belo Horizonte, v. $18, \quad$ n. $1, \quad$ p. 131-158, 2018. Disponível em: https://www.scielo.br/j/rbla/a/BzL9Srv4STd9vzWw5cC3tVB/?lang=pt. Acessado em: 30 ago. 2021.

FONSECA, P. H.; LOWEN, I. M. V.; LOURENÇO, M. L.; PERES, A. M. Cultura organizacional na área da saúde: um estudo bibliométrico. Revista Scielo Brasil, Rio de Janeiro, v. 42, n. 116, p. 318-330, 2018. Disponível em: https://www.scielo.br/j/sdeb/a/6jMsFwbNBs9P9rBkJRdSYhd/?lang=pt. Acessado em: 05 set. 2021.

RC: 102274

Disponível em:

https://www.nucleodoconhecimento.com.br/administracao/conscientizacao-

socioambiental 
GOMES, G. A. F. G. Estratégia de Vantagem Competitiva: um estudo por meio do modelo aplicado a um hotel. 2019. Monografia (Bacharel em Administração) Universidade Federal Rural do Semi-Árido, Mossoró, RN, 2019.

GUIMARÃES, C.; VIANA, L. S. COSTA, P. H. de S. Os desafios da consciência ambiental: o marketing verde em questão. C@LEA - Cadernos de Aulas do LEA, Ilhéus, n. 4, p. 94-104, 2015.

LARANJEIRA, M. I. A. Demanda na Retirada de Água, Consumo e Lançamento de Efluentes pelas Indústrias de Manaus através dos Cadastros de Usuários. 2019. Dissertação (Mestre em Gestão e Regulação de Recursos Hídricos) Universidade do Estado do Amazonas - UEA, Manaus, AM, 2019.

LARENTIS, F.; ANTONELLO, C. S. SLONGO, L. A. Cultura organizacional e marketing de relacionamento: uma perspectiva interorganizacional. Revista Brasileira de Gestão de Negócios, São Paulo, v. 20, n. 1, p. 37-56, 2018. Disponível em: <https://www.scielo.br/j/rbgn/a/BCcLDqFh9hyfVbctCFNsRys/abstract/?lang=pt> Acessado em: 05 set. 2021.

LOBO, A. M. M. S. Desenvolvimento de Produtos com Novos Materiais Poliméricos Biodegradáveis. 2018. Dissertação (Mestrado em Engenharia Mecânica) - Instituto Superior de Engenharia de Lisboa, Lisboa, 2018.

MARMO, M. A. de A. Estratégias de Melhoria do Desempenho Comercial em uma Empresa Prestadora de Serviços de Marketing Digital. São Paulo, Dissertação (Mestrado em Empreendedorismo do Departamento de Administração) Programa de Pós-graduação em Ciências, 2021.

MARTINS, A. A. de M. et al. Análise da qualidade microbiológica da água e da superfície de bebedouros de um parque localizado na região de Sorocaba São Paulo: há riscos à saúde? Revista Multidisciplinar da Saúde (RMS), São Paulo, v. 2, n. 04, pp. 01-12, 2020. Disponível em: 
<https://revistas.anchieta.br/index.php/RevistaMultiSaude/article/view/1622> Acessado em: 26 set. 2021.

MENEZES, A. H. N.; DUARTE, F. R.; CARVALHO, L. O. R. SOUZA, T. E. S. Metodologia científica: teoria e aplicação na educação a distância. Petrolina: Universidade Federal do Vale do São Francisco, 2019.

MENEZES, R. G. L. A. B. e. Estudo exploratório sobre a aplicação de estratégias Inbound Marketing pelas empresas e pelos profissionais de marketing digital. 2018. Monografia (Mestrado em Marketing Digital) - Programa de Pós-Graduação em Marketing Digital, Instituto Superior de Contabilidade e Administração de Porto, Porto, 2018.

MEZZALIRA, J. R. K. Sistema de Gestão dos Recursos (ERP) e aplicabilidade nos setores de estoque e planejamento da produção. 2017. Monografia(Bacharel em Administração) - Universidade de Santa Cruz do Sul, Santa Cruz do Sul, RS, 2017.

MINAYO, M. C. de S. COSTA, A. P. Fundamentos Teóricos das Técnicas de Investigação Qualitativa. Revista Lusófona de Educação, Campo grande, v. 40, n. 40, p. 139-153, 2018.

NASCIMENTO, A. A. Análise do Gênero Cinematográfico Cli-Fi e como ele contribui na Conscientização das Mudanças Climáticas. Niterói, Dissertação (Bacharelado em Geografia) - Universidade Federal Fluminense, Niterói, RJ, 2021.

NASCIMENTO, L. M. do; SILVA, V. A. da; PIVETTA, N. P.; SCHERER, F. L. A Percepção dos Consumidores em Relação às Estratégias de Marketing Desenvolvidas por uma Empresa de Produtos Naturais e Orgânicos. Revista Brasileira de Marketing, São Paulo, vol. 16, núm. 2, pp. 168-179, 2017. Disponível em <http://www.redalyc.org/articulo.oa?id=471755324006> Acessado em: 04 set. 2021.

RC: 102274

Disponível em:

https://www.nucleodoconhecimento.com.br/administracao/conscientizacao-

socioambiental 
OLIVEIRA, M. A. et al. A Sustentabilidade e a Responsabilidade Social das Empresas: lucratividade para as organizações e geração de benefícios sociais. X Congresso Nacional de Excelência em Gestão, 2014, Rio de Janeiro. Anais do X Congresso Nacional de Excelência em Gestão, Rio de Janeiro, 2014.

RODRIGUES, B. C. et al. Análise da Lavagem Ecológica à luz dos conceitos de sustentabilidade, empreendedorismo, inovação e sustentabilidade. Revista de Gestão e Operações Produtivas, Rio de Janeiro, v. 2, p. 14-29, 2016.

RUWER, L. D. Grau de Consciência Ambiental e Consumo Ecológico na Comunidade Universitária de Caxias do Sul. 2013. Monografia (Especialização em Educação Ambiental) - Universidade Federal de Santa Maria, Santa Maria, RS, 2013.

SANTOS, A. C. de S.; REYES JUNIOR, E. A influência do endomarketing na motivação dos colaboradores para a responsabilidade social. In:IX Congresso Nacional de Excelência em Gestão, 2013, Rio de Janeiro. Anais do IX Congresso Nacional de Excelência em Gestão. Rio de Janeiro, 2013.

SANTOS, I. E. dos. Manual de métodos e técnicas de pesquisa científica. Niterói: Impetus, 2016.

SILVA, M. G. J. Marketing social interno relacionado a questões ambientais: uma investigação numa instituição federal de ensino superior. 2016. Monografia (Mestrado em Administração) - Mestrado Profissional em Administração da Escola de Administração, Universidade Federal da Bahia, Salvador, BA, 2016.

SILVA, R. C. P. da; SANTOS, J. P. de O.; MELLO, D. P. de; EL-DEIR, S. G. Resíduos Sólidos: Tecnologias e Boas Práticas de Economia Circular. Recife: EDUFRPE, 2018. 
SILVA, S. M. B. da. O Endomarketing como fator de sucesso nas Organizações: o impacto no empenhamento e na satisfação dos clientes internos da empresa PT PRO. 2013. Monografia (Mestrado em Publicidade e Marketing) - Programa de Mestrado em Publicidade e Marketing, Instituto Técnico de Lisboa, 2013.

SIQUEIRA, A. Inbound Marketing. Disponível em: https://resultadosdigitais.com.br/especiais/inbound-marketing/\#. Acessado em: 04 set. 2021.

SIQUEIRA, É. S.; DINIZ, E. H. Equity Crowdfunding no Brasil: características dessa modalidade de investimentos, novos aspectos regulatórios e o perfil do investidor. In: XX SemeAD - Seminários em Administração, 2017, São Paulo. Anais do XX SemeAD - Seminários em Administração. São Paulo: FEA, 2017.

SOUZA, D. de M.; CARVALHO, L. G. de; BASTOS, C. M. de A. M. A Importância do Endomarketing nas Organizações de Pequeno Porte. Revista Científica Interdisciplinar Múltiplos Acessos, v. 4, n. 2, p. 135-203, 2019. Disponível em: <http://www.multiplosacessos.com/multaccess/index.php/multaccess/article/view/127 $>$ Acessado em: 05 set. 2021.

SOUZA, M. B. O uso da teoria de opções reais na avaliação de projetos de investimentos para implementação de sistemas ERP. 2014. Tese (Doutorado em Administração de Empresas) - Programa de Pós-Graduação em Administração de Empresas da Universidade Presbiteriana Mackenzie, 2014.

WENTZ, V. L.; FROEHLICH, C. Cultura Organizacional: um estudo na empresa MGO. Revista Gestão E Desenvolvimento, v. 9 n. 2, pp. 131-144, 2012. Disponível em:<https://periodicos.feevale.br/seer/index.php/revistagestaoedesenvolvimento/artic le/view/1022/1406> Acessado em: 03 set. 2021.

ZANELLA, L. C. H. Metodologia de Pesquisa. 2a ed. reimp. Florianópolis: Departamento de Ciências da Administração/UFSC, 2013.

RC: 102274

Disponível em:

https://www.nucleodoconhecimento.com.br/administracao/conscientizacaosocioambiental 
Enviado: Outubro, 2021.

Aprovado: Novembro, 2021.

RC: 102274

Disponível em:

https://www.nucleodoconhecimento.com.br/administracao/conscientizacaosocioambiental 